\title{
Innovations
}

Psychotherapy and Psychosomatics
Psychother Psychosom 2019;88:341-349

DOI: $10.1159 / 000504024$
Received: September 10,2019

Accepted after revision: October 10, 2019

Published online: October 30, 2019

\section{Mental Pain as a Transdiagnostic Patient-Reported Outcome Measure}

\author{
Giovanni A. Fava $^{\mathrm{a}}$ Elena Tomba $^{\mathrm{b}}$ Eva-Lotta Brakemeier ${ }^{\mathrm{c}, \mathrm{d}}$ Danilo Carrozzino $^{\mathrm{e}}$ \\ Fiammetta Cosci ${ }^{f}$ Ajándék Eöryg ${ }^{g}$ Tommaso Leonardi ${ }^{h}$ Isabel Schamong ${ }^{d}$ \\ Jenny Guidi ${ }^{b}$
}

${ }^{a}$ Department of Psychiatry, University at Buffalo, State University of New York, Buffalo, NY, USA; ${ }^{b}$ Department of Psychology, University of Bologna, Bologna, Italy; ${ }^{C}$ Department of Clinical Psychology and Psychotherapy, Universitat Greifswald, Greifswald, Germany; ${ }^{d}$ Department of Clinical Psychology and Psychotherapy and Center for

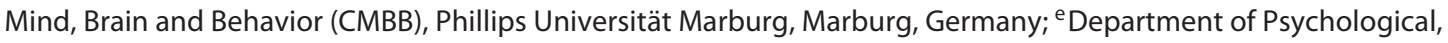
Health and Territorial Sciences, University G. d'Annunzio of Chieti-Pescara, Chieti, Italy; ${ }^{\mathrm{f}}$ Department of Health Sciences, University of Florence, Florence, Italy; ${ }^{9}$ Department of Family Medicine, Semmelweis University, Budapest,

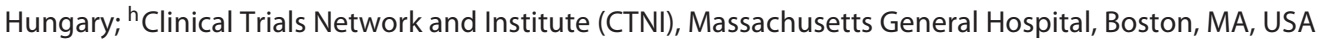

\author{
Keywords \\ Mental pain · Patient-reported outcomes - Clinimetrics . \\ Depression · Mental Pain Questionnaire
}

\begin{abstract}
Patient-reported outcomes (PROs) refer to any report coming directly from patients about how they function or feel in relation to a health condition or its therapy. PROs have been applied in medicine for the assessment of the impact of clinical phenomena. Self-report scales and procedures for assessing physical pain in adults have been developed and used in clinical trials. However, insufficient attention has been dedicated to the assessment of mental pain. The aim of this paper is to outline the implications that assessment of mental pain may entail in psychiatry and medicine, with particular reference to a clinimetric index. A simple 10-item selfrating questionnaire, the Mental Pain Questionnaire (MPQ), encompasses the specific clinical features of mental pain and shows good clinimetric properties (i.e., sensitivity, discriminant and incremental validity). The preliminary data
\end{abstract}

suggest that the MPQ may qualify as a PRO measure to be included in clinical trials. Assessment of mental pain may have important clinical implications in intervention research, both in psychopharmacology and psychotherapy. The transdiagnostic features of mental pain are supported by its association with a number of psychiatric disorders, such as depression, anxiety, eating disorders, as well as borderline personality disorder. Further, addressing mental pain may be an important pathway to prevent and diminish the opioid epidemic. The data summarized here indicate that mental pain can be incorporated into current psychiatric assessment and included as a PRO measure in treatment outcome studies.

(c) 2019 S. Karger AG, Basel

\section{Introduction}

There has been growing emphasis on patient-reported outcomes (PROs) - any report coming directly from patients about how they function or feel in relation to a health condition or its therapy [1]. Patients' perspective

\section{KARGER}

(c) 2019 S. Karger AG, Basel 
may support analyses of efficacy and effectiveness, examinations of quality of care, and pharmacovigilance. Some PROs focus on self-rated evaluation of specific diseaserelated conditions, such as cancer, pain, or depression. Other indices are focused on more general perceptions, such as quality of life. PROs are also clinically useful for detecting the burden and impact of symptoms on quality of life and psychological well-being of patients [2]. Physical pain is frequently assessed, generally for determining what type of intervention is likely to affect subjective perception of pain best. Self-report scales and procedures for assessing physical pain in adults have been developed and used in clinical trials [3]. PROs are part of the general psychosomatic approach [4] that considers how a patient perceives symptoms and how this appraisal affects his/ her functioning and relationships with others as part of the disease process [5-7]. The need to include consideration of functioning in daily life, productivity, performance of social roles, intellectual capacity, emotional stability, and well-being has emerged as a crucial part of clinical investigation and patient care [5]. Psychosomatic medicine pioneered the self-rated evaluation of psychological status in medical conditions. In psychiatry, selfrating scales, long before the appearance of PROs, have been part of assessment tools for clinical trials $[8,9]$. A number of sensitive and valid instruments have been developed for assessing mood, anxiety, and other psychological symptoms $[9,10]$. However, assessment of mental pain has been neglected by clinical studies in psychiatry $[11,12]$. For instance, the comprehensive Handbook of Psychiatric Measures [13] did not include a specific instrument for mental pain.

The aim of this paper is to outline the clinical implications that assessment of mental pain may entail in psychiatry and medicine, with particular reference to a clinimetric index that may have considerable potential in pursuing such a goal.

\section{Clinical Characterization of Mental Pain}

There have been various definitions of mental pain in the literature, where, in addition to mental pain, terms such as psychic pain, emotional pain, psychological pain, social pain, emptiness, psychache, internal perturbation, and psychological quality of life have been used to refer to this construct $[11,14,15]$.

Sometimes, according to such definitions the concept is placed in a specific context. Shneidman [16] defined it as "psychache," an acute state of intense psychological pain associated with feelings of guilt, anguish, fear, panic, loneliness, and helplessness, which is at the core of the suicidal process. Orbach et al. [17] defined mental pain as "a wide range of subjective experiences characterized as a perception of negative changes in the self and its function that is accompanied by strong negative feelings," and completed suicide can be viewed as a means of alleviating a painful internal state. Indeed, higher levels of psychological pain were found to be associated with suicidal ideations and acts [18].

Other definitions are broader. According to Cassel [19], suffering can be defined as a state of severe distress that occurs when an impending destruction of the person is perceived. "Suffering is experienced by persons, not merely by bodies, and has its source in challenges that threaten the intactness of the person as a complex social and psychological entity" [19]. As Sensky [20] noted, the term "suffering", however, may have different meanings to different people. Expressions such as "suffering from intense pain," "suffering from a terminal illness," or even "suffering a hangover" are indicative of these ambiguities.

Meerwijk and Weiss [21] attempted to identify some common characteristics of psychological pain (they preferred this term to mental pain), that were identified in unpleasant feelings, appraisal of an inability or deficiency, and its features of unsustainability. They advocated an operational and consensus definition beyond the various conceptualizations of psychological pain [21].

Engel [22] pointed out that grief is a cause of mental pain, produces a variety of bodily and psychological symptoms, and interferes with our ability to function effectively. Grief may occur after the loss of a valued object, being it a loved person, a cherished possession, a job, status, home, country, an ideal, or a part of the body. Schmale [23] underscored that grieving, as with other forms of loss and life change, is a highly personal reaction, which is based on individual past experiences, current life circumstances, and future aspirations. Medical illness may constitute a significant loss, particularly with regard to the state of good health and/or well-being [23].

Engel [22] wondered whether grief could be considered as a disease and challenged its traditional conceptualization, which tends to be restricted to what can be understood or recognized by the physician $[22,24]$. Similarly, mental pain may be a universal experience that has a natural course and may become the source of positive insights that prelude to adaptive changes.

The borderland between mental pain and pain referred to the body is of difficult definition, since pain always involves a psychological component [25]. Engel [25] 
defined pain "as a psychological experience involving the concepts of injury and suffering, but not contingent on actual physical injury. The idea of injury as well as the need to suffer may lead to pain, just as a real lesion or injury may do. Similarly, the need not to suffer or not to accept the fact that an injury is painful may render a "painful" injury "painless."

\section{The Link between Mental and Physical Pain}

According to the definition of the International Association for the Study of Pain (IASP), "pain is an unpleasant sensory and emotional experience associated with actual or potential tissue damage or described in terms of such damage" [26]. This definition clearly determines that in addition to nociceptive activation of the brain, pain is an individual and internal experience, which is consciously perceived, modulated, and transformed according to its emotional context [27]. Moreover, the clinical manifestations of pain can be seen as the result of the complex interplay between biological factors, psychological processes, and social influences. Pain-related neural brain networks fluctuate spontaneously, therefore the pain experience is a result of dynamic communication of networks shaping cognition and behavior, called the "pain connectome" [28]. When acute pain arises, the etiology can be defined in most cases. However, chronic pain may occur in the absence of prior tissue injury and may be the result of dyssynchrony and disruption of the pain connectome [29].

Recent neuroimaging studies have shown that physical pain evoked by nociceptive stimuli involves similar brain regions activated by various emotional and behavioral states [27]. This hierarchical, multilevel neural network is responsible for the process of experiencing physical pain (spinothalamic tract to posterior thalamus - 1st level). This information is further processed and enriched with conscious perception and attentive and cognitive modulation (anterior cingulate cortex, insula, prefrontal cortex, posterior parietal cortex - 2nd level), leading to somatic or vegetative responses. Finally, pain perception and modulation are enriched by the emotional context and individual psychological factors (orbitofrontal cortex, perigenual anterior cingulate cortex, anterolateral prefrontal cortex - 3rd level) to formulate individual pain memory; 2 nd and 3rd level brain regions modulate the incoming nociceptive stimuli as either inhibitory or facilitatory through interactions with descending tracts in the spinal cord [27].

Mental Pain
In many cases pain awareness in chronic pain ("chronic pain phenotype") is the result of ongoing subconscious changes in brain function modulated by internal (e.g., genetic, inflammatory, repeated nociceptive events) and external (e.g., environment, socioeconomic levels) processes [29]. In healthy populations, intrinsic brain activity organizes brain networks to interpret, respond, and predict environmental stimuli $[30,31]$. This intrinsic activity shows similar networks across populations and over time and does not have a pain phenotype, although there are differences in relation to sex and certain psychological factors (substance use disorders and mood disorders) [29]. Early development injuries (e.g., early child amputation) and acute pain attacks (e.g., migraine) may result in delayed onset of chronic pain, which is related to the underlying alterations in brain network efficiency, connectivity, and strength [29]. Psychological factors, particularly depression, may reorder the neural network, producing a chronic pain phenotype without a history of prior pain [29]. Environmental factors may also play an important role in the development of pain. Chronic therapeutic use of opioids (e.g., in migraine or in chronic pain) may lead to hyperalgesia and further pain chronicity [29]. Physical and psychological trauma accompanied by negative emotions (sexual abuse, torture) may contribute to chronic dysfunction in the brain, resulting in generalized dysfunctional pain modulation with consequent chronic pain at nearly the same level as at the time of the initiating event $[29,32,33]$. When the structural and chemical changes in the brain and the dyssynchrony and disruption of networks reach a tipping point, then conscious pain develops [29].

\section{Patient-Reported Outcome Measures}

Engel [25] acknowledges that a limiting factor in patient description during an interview is the patient's verbal capacity: "one must accept the fact that some persons simply lack the vocabulary and fluency to report much beyond the fact that they are in pain." This particularly applies to the description of mental pain by patients who present with alexithymic features [5]. There are two methods for assessing mental pain that may be subsumed under the rubric of PRO measures and may complement clinical interviewing.

One is provided by self-rating questionnaires. A number of psychometric instruments have been developed: the Psychological Pain Assessment Scale (PPAS) [16], the Multiple Visual Analog Scale (MVAS) [16], the Psych- 
Table 1. The Mental Pain Questionnaire (MPQ)

\begin{tabular}{lll}
\hline Mental Pain Questionnaire (MPQ) & \\
\hline Mental or psychological pain is an experience that is part of life. It is different from physical pain. We would \\
like to learn about your experience of mental pain in the past week. There is no right or wrong answer. Please \\
work quickly. \\
\hline 1. I feel pain & yes & no \\
2. My heart is broken & yes & no \\
3. I will never find again what I have lost & yes & no \\
4. My pain is everywhere & yes & no \\
5. My pain is with me all the time & yes & false \\
6. I cannot understand why I feel this pain & true & no \\
7. I feel empty & yes & false \\
8. My life makes no sense & true & false \\
9. My pain will never go away & true & false \\
10. The only way to stop my pain is to die & true &
\end{tabular}

Scoring for each item: yes/true $=1$, no/false $=0$; total score range: $0-10$. From Fava [47]

ache Scale (PAS) [34], the Orbach and Mikulincer Mental Pain Scale (OMMP) [35], the Tolerance for Mental Pain Scale (TMPS) [36], and the Mee-Bunney Psychological Pain Assessment Scale (MBPPAS) [37]. Many of the validation studies have been conducted in relation to suicide attempters.

Another type of measure does not rely on language skills and can be used to rapidly elicit patients' appraisals of their suffering [38, 39]. Büchi et al. [38-41] have devised a measure called the Pictorial Representation of Illness and Self Measure (PRISM), which, in validation studies [41], behaves as expected of a measure of suffering and fits well with Cassel's conceptualization of suffering [19, 42].

At present, however, there is insufficient evidence to indicate that any of these specific instruments satisfies the requirements for inclusion as PROs in clinical trials, according to guidelines [43].

\section{Development of a Clinimetric Index}

Clinimetrics, the science of clinical measurements, offers important opportunities for assessing clinical phenomena such as mental pain $[10,44,45]$. Such assessment is generally neglected in standard psychiatric and medical evaluations, where exclusive reliance on the symptoms of the psychiatric diagnostic criteria may not reflect the clinical picture of patients in practice [46].

A simple clinimetric index (a 10-item yes/no questionnaire), the Mental Pain Questionnaire (MPQ) (Table 1), was developed $[47,48]$. In psychometrics, homogeneity of components, measured by statistical tests such as Cronbach's alpha, is often regarded as the most important requirement for a rating scale. However, the same properties that give a scale a high score for homogeneity may obscure its ability to detect changes [44]. In clinimetrics, homogeneity of components is not requested and single items may be weighed in different ways: what matters is the capacity of an index to discriminate between different groups of subjects and to reflect changes in experimental settings such as psychotropic drug or psychotherapy trials $[9,49]$. As a result, on the basis of the available literature, some specific features of mental pain in the clinical setting were identified.

1 Presence of mental pain. This is the first clinical requirement. Questions such as "Do you feel pain and suffering in your mind that goes beyond what one may experience in life from time to time? How would you describe it? How does it compare with physical pain?" may be a helpful start. In our clinical experience patients are unlikely to spontaneously report mental pain unless they are specifically questioned about it. When they are encouraged, they may provide very vivid descriptions.

2 Feeling of being wounded. Mental pain has been characterized as a state of "feeling broken" that involves the experience of being wounded, with loss of self and disconnection from others $[14,23]$. Expressions such as "my heart is broken" reflect this state.

3 Sense of helplessness and hopelessness. Mental pain may be increased by feelings of helplessness (the perception of being unable to cope with some pressing problems and/or of lack of adequate support from oth- 
ers) or hopelessness (the consciousness of having failed to meet expectations associated with the conviction that there are no solutions for current problems and difficulties) $[5,50]$. Hopelessness/giving-up may increase the perception of mental pain and thus needs to be distinguished from helplessness [51].

4 Pain location. One of the characteristics of mental pain is the fact that it cannot be localized in a part of the body. The term "central pain" has been used, particularly in reference to depression, where the system is disinhibited, with distress arising from stimuli that were previously non-aversive [52-54].

5 Duration of pain. It is of crucial importance how mental pain is perceived by the individual as such to get an idea of its duration, persistence, and potential chronicity. Questions such as "Does it hurt all the time or in specific moments? Does it occur every day or less frequently? Is there anything that makes it worse? Is there anything that makes it better?" may provide further helpful specifiers.

6 Relation to events and situations. Some patients may date its beginning in relation to a certain event or situation, whereas other people are unable to track a specific time of onset. Lack of understanding the occurrence of mental pain is likely to increase the perception of pain.

7 Feelings of emptiness. Feeling numb or empty may be another clinical characteristic of mental pain. Such feelings were found to differentiate major suicide repeaters and non-major suicide repeaters [55].

8 Loss of meaning of life. Emptiness may be increased by loss of meaning in life [56]. Frankl [56] suggested that suffering terminates at the moment a meaning is found for it.

9 Irreversibility of pain. When mental pain is of long duration it may engender the conviction of its irreversibility, as well as fears and intolerance of suffering.

10 Relationships with suicidal ideations. Suicide risk is much higher when the general psychological and emotional pain reaches intolerable intensity $[18,57,58]$ in relation to the individual pain tolerance threshold [16], particularly in the context of major mood disorders [59]. Patients may come to believe that the only way to stop pain is to die.

These 10 characteristics were translated into 10 simple self-rated formulations. The MPQ has shown good clinimetric properties when administered in a clinical population of 200 migraine patients [60], particularly sensitivity in discriminating between patients with or without psychological distress, and incremental validity (according

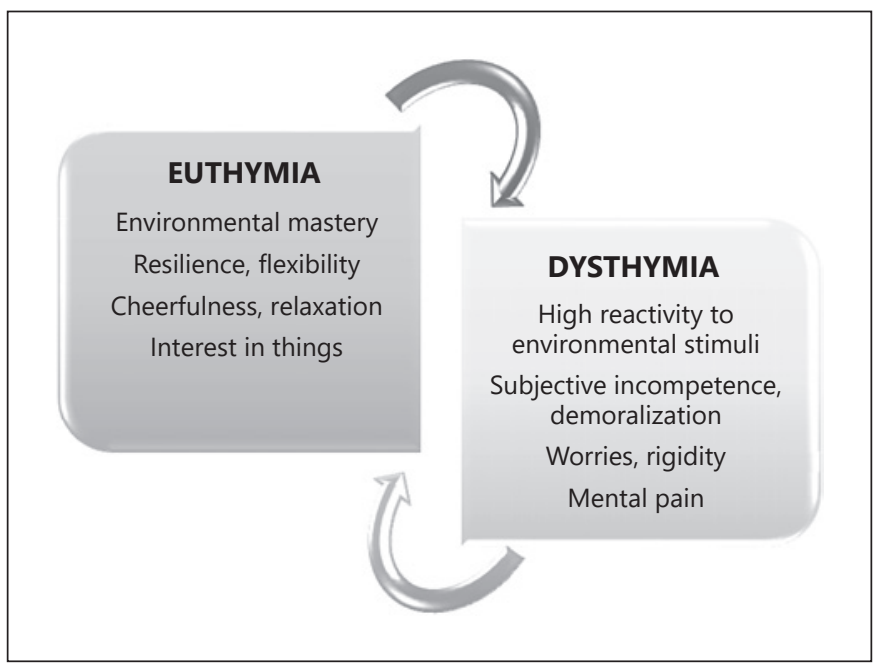

Fig. 1. Transdiagnostic balance between euthymia and dysthymia.

to which each distinct aspect of psychological measurement should deliver a unique increase in information in order to qualify for inclusion). In another investigation on 200 primary care patients [61], the MPQ significantly discriminated between patients presenting with at least one DSM-5 [62] or Diagnostic Criteria for Psychosomatic Research (DCPR) [5] diagnosis and those who had no diagnosis, displaying good sensitivity and discriminating between different patient subgroups. There were highly significant correlations between the MPQ and both observer- and self-rated scales of psychological distress [60, 61], such as the Clinical Interview for Depression [63] and the Psychosocial Index [64]. The MPQ was also significantly negatively correlated with the Euthymia Scale $[65,66]$. These preliminary data suggest that the MPQ may satisfy the clinimetric requirements to qualify as a PRO measure.

\section{The Transdiagnostic Features of Mental Pain}

In 1967, Eysenck [67] referred to neuroticism and introversion by the term "dysthymia." The term then became synonymous with chronic depression, but its original definition [67] provides the conceptual ground for the clinical transdiagnostic balance between euthymia (characterized by environmental mastery, resilience, flexibility, cheerfulness, relaxation, interest in things) and dysthymia (encompassing high reactivity to environmental stimuli, subjective incompetence, demoralization, rigidity, worries, and mental pain) [68, 69] (Fig. 1). 
The transdiagnostic features of mental pain are supported by its association with a number of psychiatric disorders. Mental pain can be considered as a specifier for DSM-5 "clinically significant distress" caused by the symptoms of a psychiatric disorder [62]. Depression is inextricably linked to its experience: patients may present with a uniquely aversive, anguished, or uncomfortable experience that is characterized by painful tension and torment $[52-54,70]$. They may become suicidal when they perceive their emotional state as painful and incapable of change.

However, mental pain can also occur independently from depression. It may be associated with anxiety disorders [61], such as in the perception of invalidism in agoraphobia or social barrier in social anxiety. In anorexia nervosa, the select mental focus on food and eating has been found to be related with emotional avoidance [71] and patients often report feeling emotionally "numb." When qualitative assessment methods were applied [72], anorexic patients reported that their illness helped them to avoid or control aversive emotions and high sensitivity to emotional pain.

Patients with borderline personality disorder have a range of intense dysphoric affects, sometimes experienced as aversive tension, including rage, sorrow, shame, panic, terror, and chronic feelings of emptiness and loneliness. These individuals can be distinguished from other groups by the overall degree of their multifaceted mental pain $[73,74]$, which has been associated with a high prevalence of reported childhood maltreatment [75]. Deliberate self-harm may serve to shift attentional focus away from emotional pain and toward physical pain [76].

Mental pain has also been described in the setting of post-traumatic stress disorder [77], obsessive-compulsive disorder [78], schizophrenia [79], and grief [22]. There may be considerable overlaps, even in brain networks, with pain of somatic origin $[11,12,80]$. The characteristics of mental pain associated with medical disease, however, have not been sufficiently explored. Engel [81] observed that some individuals are more prone than others to use physical pain as a psychic regulator, whether the pain includes a peripheral source of stimulation or not. These patients have been defined as "pain-prone" $[81,82]$.

Finally, the subjective experience of mental pain may be influenced by spiritual and religious factors. According to Wachholtz and Fitch [83], chronic pain conditions may be influenced by religious beliefs and active use of prayer may be a primary form of coping. Religious/spiritual beliefs, however, may have powerful negative impact on the perception of pain. The Italian scholar of biblical studies Ortensio da Spinetoli [84] underscored how a certain interpretation of the Catholic religion may link suffering to guilt and expiation as a well-deserved punishment, despite lack of any biblical evidence to support such a stance.

\section{Treatment of Mental Pain}

Assessment of mental pain may have important implications in intervention research, particularly in psychopharmacology and psychotherapy, and yet it has been ignored. For instance, depressed patients frequently report that treatment with antidepressant drugs yields substantial relief of their mental pain. This would be consistent with the decrease in reactivity to social environment that has been found in placebo-controlled trials with antidepressant drugs using Paykel's Clinical Interview for Depression [63]. It would also be consistent with Carroll's neurobiological model of central pain [54]. In the depressed phase, the central nervous system is seen as disinhibited, so that stimuli that previously were non-aversive are experienced as distressing and lead to agitation, pathological guilt, and hopelessness [54]. The findings of van Heeringen et al. [85] indicate that dorsolateral hyperactivity is associated with increased levels of mental pain in depression. It is a common clinical experience to observe relief of mental pain by the use of other psychotropic drugs, such as benzodiazepines $[86,87]$ or antipsychotics [88]. Since improvement in variables associated with mental pain may also occur with placebo [89], one may wonder what is the specific role of psychopharmacology. We need to test and compare psychotropic drugs in randomized placebo-controlled trials, with mental pain as a PRO.

With regard to psychotherapy, relief of mental pain has been associated with non-specific therapeutic ingredients such as attention and opportunities for disclosure in a high arousal state $[5,49]$. In recent years, there has been increasing interest in the role of positive affects in pain and its treatment $[90,91]$. Since positive affects have been found to attenuate both the perception of physical pain and its psychological responses [90], it is conceivable, and yet to be tested, that a specific psychotherapeutic strategy for modulating well-being, Well-Being Therapy (WBT), may counteract the manifestations of mental pain [47]. It is also conceivable that appropriately using spiritual resources [92] may lead to clinical improvement. 
In recent years, the opioid abuse epidemic has gained increasing visibility [93]. In the USA, in 2016 more than 11 million Americans misused prescription opioids, and opioid-related death has claimed more than 300,000 lives since 2000 . The majority of people started with painkillers, and problematic prescription of opioids is often cited as a primary contributor to the current epidemic [94]. Individuals with chronic pain are commonly prescribed opioids for its treatment and are at risk for developing opioid abuse [94]. The role of mental pain in such a population has been insufficiently explored, even though it can be inferred by the use of antidepressant drugs or related substances in the management of somatic pain [12]. Addressing mental pain, whether accompanied or not by somatic manifestations, may be an important pathway to prevent and diminish the opioid epidemic. Garland et al. [95] conducted a randomized controlled trial involving a psychotherapeutic protocol geared to mindfulness and positive emotions compared to a support group in chronic pain patients who abused opioids. The intervention significantly reduced opioid misuse and craving while decreasing pain syndromes.

\section{Conclusions}

The data we summarized indicate that there is a pressing need for research assessing mental pain in medical and psychiatric settings. According to the clinimetric approach, mental pain should be incorporated, among other important psychological variables, into current psychiatric assessment and may yield specific clinical features of patients' psychological distress. Further, mental pain should be included as a PRO measure in treatment outcome studies and may become a very important indicator of the effectiveness and usefulness of interventions, particularly with regard to psychopharmacology and psychotherapy.

\section{Disclosure Statement}

All authors have no conflicts of interest to declare.

\section{Author Contributions}

G.A.F. wrote the first draft of the manuscript, with the support of E.T. and J.G. All authors contributed to the final version of the manuscript.

\section{References}

1 Basch E. Patient-reported outcomes - harnessing patients' voices to improve clinical care. N Engl J Med. 2017 Jan;376(2):105-8.

2 Bech P, Timmerby N. An overview of which health domains to consider and when to apply them in measurement-based care for depression and anxiety disorders. Nord J Psychiatry. 2018 Jul;72(5):367-73

3 Jensen MP, Karoly P. Self-report scales and procedures for assessing pain in adults. In: Turk DC, Melzack R, editors. Handbook of pain assessment. 2nd ed. New York (NY): Guilford; 2001. pp. 15-34.

4 Mehran R, Baber U, Dangas G. Guidelines for Patient-Reported Outcomes in clinical trial protocols. JAMA. 2018 Feb;319(5):450-1.

5 Fava GA, Cosci F, Sonino N. Current psychosomatic practice. Psychother Psychosom. 2017;86(1):13-30.

6 McEwen BS. Epigenetic interactions and the brain-body communications. Psychother Psychosom. 2017;86(1):1-4.

7 Horwitz RI, Hayes-Conroy A, Singer BH. Biology, social environment, and personalized medicine. Psychother Psychosom. 2017; 86(1):5-10.

8 Bech P. Mood and anxiety in the medically ill. Adv Psychosom Med. 2012;32:118-32.

9 Fava GA, Tomba E, Bech P. Clinical pharmacopsychology: conceptual foundations and emerging tasks. Psychother Psychosom. 2017; 86(3):134-40

10 Tomba E, Bech P. Clinimetrics and clinical psychometrics: macro- and micro-analysis. Psychother Psychosom. 2012;81(6):333-43.

11 Tossani E. The concept of mental pain. Psychother Psychosom. 2013;82(2):67-73.

12 Yager J. Addressing patients' psychic pain. Am J Psychiatry. 2015 Oct;172(10):939-43.

13 Rush AJ, First MB, Blacker D, editors. Handbook of Psychiatric Measures. 2nd ed. Washington (D.C.): American Psychiatric Publishing, Inc; 2008.

14 Bolger E. Grounded theory analysis of emotional pain. Psychother Res. 1999;9(3):34262.

15 Macdonald G, Leary MR. Why does social exclusion hurt? The relationship between social and physical pain. Psychol Bull. 2005 Mar; 131(2):202-23.

16 Shneidman ES. Suicide as psychache. J Nerv Ment Dis. 1993 Mar;181(3):145-7.

17 Orbach I, Mikulincer M, Gilboa-Schechtman E, Sirota P. Mental pain and its relationship to suicidality and life meaning. Suicide Life Threat Behav. 2003;33(3):231-41.

18 Ducasse D, Holden RR, Boyer L, Artero S, Calati R, Guillame S, et al. Psychological pain in suicidality: a meta-analysis. J Clin Psychiatry. 2018 May/Jun;79(3):16r10732.
19 Cassel EJ. The nature of suffering and the goals of medicine. N Engl J Med. 1982 Mar; 306(11):639-45.

20 Sensky T. Suffering. Int J Integr Care. 2010 Jan;10 Suppl:e024.

21 Meerwijk EL, Weiss SJ. Toward a unifying definition: response to 'The concept of mental pain'. Psychother Psychosom. 2014;83(1):62-3.

22 Engel GL. Is grief a disease? A challenge for medical research. Psychosom Med. 1961 JanFeb;23(1):18-22.

23 Schmale AH. Reactions to illness: convalescence and grieving. Psychiatr Clin North Am. 1979 Aug;2(2):321-30.

24 Fava GA, Sonino N. From the lesson of George Engel to current knowledge. The biopsychosocial model 40 years later. Psychother Psychosom. 2017;86(5):257-9.

25 Engel GL. Pain. In: Mac Bryde CM, editor. Signs and symptoms: applied pathological physiology and clinical interpretation. Philadelphia: Lippincott; 1969. pp. 44-6.

26 International Association for the Study of Pain (IASP) link to pain definition [cited 2019 Sep. 6]. Available from: https://www.iasp-pain.org/ Education/Content.aspx?ItemNumber=1698.

27 Hooten WM. Chronic Pain and Mental Health Disorders: Shared Neural Mechanisms, Epidemiology, and Treatment. Mayo Clin Proc. 2016 Jul;91(7):955-70. 
28 Kucyi A, Davis KD. The dynamic pain connectome. Trends Neurosci. 2015 Feb;38(2): 86-95.

29 Borsook D, Youssef AM, Barakat N, Sieberg $\mathrm{CB}$, Elman I. Subliminal (latent) processing of pain and its evolution to conscious awareness. Neurosci Biobehav Rev. 2018 May;88:1-15.

30 Raichle ME. The restless brain: how intrinsic activity organizes brain function. Phil Trans R Soc B. 2015 May;370(1668):20140172

31 Peters A, McEwen BS, Friston K. Uncertainty and stress: why it causes diseases and how it is mastered by the brain. Prog Neurobiol. 2017 Sep;156:164-88.

32 Olsen DR, Montgomery E, Carlsson J, Foldspang A. Prevalent pain and pain level among torture survivors: a follow-up study. Dan Med Bull. 2006 May;53(2):210-4.

33 Marin MF, Song H, VanElzakker MB, Staples-Bradley LK, Linnman C, Pace-Schott EF, et al. Association of resting metabolism in the fear neural network with extinction recall activations and clinical measures in trauma-exposed individuals. Am J Psychiatry. 2016 Sep; 173(9):930-8.

34 Holden R, Mehta K, Cunningham E, McLeod L. Development and preliminary validation of a scale of psychache. Can J Behav Sci. 2001 Oct;33(4):224-32.

35 Orbach I, Mikulincer M, Sirota P, GilboaSchechtman E. Mental pain: a multidimensional operationalization and definition. Suicide Life Threat Behav. 2003;33(3):219-30.

36 Meerwijk EL, Mikulincer M, Weiss SJ. Psychometric evaluation of the Tolerance for Mental Pain Scale in United States adults. Psychiatry Res. 2019 Mar;273:746-52.

37 Mee S, Bunney BG, Bunney WE, Hetrick W, Potkin SG, Reist C. Assessment of psychological pain in major depressive episodes. J Psychiatr Res. 2011 Nov;45(11):1504-10.

38 Büchi S, Sensky T. PRISM: pictorial Representation of Illness and Self Measure. A brief nonverbal measure of illness impact and therapeutic aid in psychosomatic medicine. Psychosomatics. 1999 Jul-Aug;40(4):314-20.

39 Sensky T, Büchi S. PRISM, a novel visual metaphor measuring personally salient appraisals, attitudes and decision-making. PLoS One. 2016 May;11(5):e0156284.

40 Büchi S, Sensky T, Sharpe L, Timberlake N. Graphic representation of illness: a novel method of measuring patients' perceptions of the impact of illness. Psychother Psychosom. 1998 Jul-Oct; 67(4-5):222-5.

41 Büchi S, Buddeberg C, Klaghofer R, Russi EW, Brändli O, Schlösser C, et al. Preliminary validation of PRISM (Pictorial Representation of Illness and Self Measure) - a brief method to assess suffering. Psychother Psychosom. 2002 Nov-Dec;71(6):333-41.

42 Cassell EJ. Diagnosing suffering: a perspective. Ann Intern Med. 1999 Oct;131(7):531-4.
43 Calvert M, Kyte D, Mercieca-Bebber R, Slade A, Chan AW, King MT, et al.; SPIRIT-PRO Group. Guidelines for inclusion of patientreported outcomes in clinical trials protocols: the SPIRIT-PRO extension. JAMA. 2018 Feb; 319(5):483-94.

44 Fava GA, Tomba E, Sonino N. Clinimetrics: the science of clinical measurements. Int $J$ Clin Pract. 2012 Jan;66(1):11-5.

45 Fava GA, Carrozzino D, Lindberg L, Tomba E. The clinimetric approach to psychological assessment: A Tribute to Per Bech, MD (19422018). Psychother Psychosom. 2018;87(6): 321-6.

46 Fava GA, Rafanelli C, Tomba E. The clinical process in psychiatry: a clinimetric approach. J Clin Psychiatry. 2012 Feb;73(2):177-84.

47 Fava GA. Well-being therapy: treatment manual and clinical applications. Basel: Karger; 2016. Available from: https://doi. org/10.1159/isbn.978-3-318-05822-2.

48 Fava GA. Well-Being Therapy: current indications and emerging perspectives. Psychother Psychosom. 2016;85(3):136-45.

49 Guidi J, Brakemeier EL, Bockting CL, Cosci F, Cuijpers P, Jarrett RB, et al. Methodological Recommendations for Trials of Psychological Interventions. Psychother Psychosom. 2018; 87(5):276-84

50 Tecuta L, Tomba E, Grandi S, Fava GA. Demoralization: a systematic review on its clinical characterization. Psychol Med. 2015 Mar; 45(4):673-91.

51 Sweeney DR, Tinling DC, Schmale AH Jr. Differentiation of the "giving-up" affectshelplessness and hopelessness. Arch Gen Psychiatry. 1970 Oct;23(4):378-82.

52 Klein DF. Endogenomorphic depression. A conceptual and terminological revision. Arch Gen Psychiatry. 1974 Oct;31(4):447-54.

53 Carroll BJ. Psychopathology and neurobiology of manic-depressive disorders. In: Carroll BJ, Barrett JE, editors. Psychopathology and the brain. New York (NY): Raven Press; 1991. pp. 265-85.

54 Carroll BJ. Brain mechanisms in manic depression. Clin Chem. 1994 Feb;40(2):303-8.

55 Blasco-Fontecilla H, Baca-García E, Courtet P, García Nieto R, de Leon J. Horror vacui: emptiness might distinguish between major suicide repeaters and nonmajor suicide repeaters: a pilot study. Psychother Psychosom. 2015;84(2):117-9.

56 Frankl VE. Man's Search for Meaning. New York: First Washington Square Press; 1963.

57 Berlim MT, Mattevi BS, Pavanello DP, Caldieraro MA, Fleck MP, Wingate LR, et al. Psychache and suicidality in adult mood disordered outpatients in Brazil. Suicide Life Threat Behav. 2003;33(3):242-8

58 de Leon J, Baca-García E, Blasco-Fontecilla $\mathrm{H}$. From the serotonin model of suicide to a mental pain model of suicide. Psychother Psychosom. 2015;84(6):323-9.

59 Joiner TE Jr, Brown JS, Wingate LR. The psychology and neurobiology of suicidal behavior. Annu Rev Psychol. 2005;56(1):287-314.
60 Svicher A, Romanazzo S, De Cesaris F, Benemei S, Geppetti P, Cosci F. Mental Pain Questionnaire: an item response theory analysis. J Affect Disord. 2019 Apr;249:226-33.

61 Guidi J, Piolanti A, Gostoli S, Schamong I, Brakemeier EL. Mental pain and euthymia as transdiagnostic clinimetric indices in primary care. Psychother Psychosom. 2019;88(4): 252-3.

62 American Psychiatric Association. Diagnostic and statistical manual of mental disorders - DSM-5. 5th ed. Arlington: American Psychiatric Publishing; 2013.

63 Guidi J, Fava GA, Bech P, Paykel E. The Clinical Interview for Depression: a comprehensive review of studies and clinimetric properties. Psychother Psychosom. 2011;80(1):1027.

64 Sonino N, Fava GA. A simple instrument for assessing stress in clinical practice. Postgrad Med J. 1998 Jul;74(873):408-10.

65 Fava GA, Bech P. The concept of euthymia. Psychother Psychosom. 2016;85(1):1-5.

66 Carrozzino D, Svicher A, Patierno C, Berrocal C, Cosci F. The Euthymia Scale: a clinimetric analysis. Psychother Psychosom. 2019;88(2): $119-21$.

67 Eysenck HJ. The biological basis of personality. Springfield (IL): Thomas; 1967.

68 Fava GA, Cosci F, Guidi J, Tomba E. Wellbeing therapy in depression: new insights into the role of psychological well-being in the clinical process. Depress Anxiety. 2017 Sep; 34(9):801-8.

69 Fava GA, Guidi J. The pursuit of euthymia. World Psychiatry. Forthcoming 2020

70 Mendels J, Cochrane C. The nosology of depression: the endogenous-reactive concept. Am J Psychiatry. 1968 May;124(11S 11):1-11.

71 Schmidt U, Treasure J. Anorexia nervosa: valued and visible. A cognitive-interpersonal maintenance model and its implications for research and practice. Br J Clin Psychol. 2006 Sep;45(Pt 3):343-66.

72 Nordbø RH, Espeset EM, Gulliksen KS, Skårderud F, Holte A. The meaning of self-starvation: qualitative study of patients' perception of anorexia nervosa. Int J Eat Disord. 2006 Nov;39(7):556-64.

73 Zanarini MC, Frankenburg FR, DeLuca CJ, Hennen J, Khera GS, Gunderson JG. The pain of being borderline: dysphoric states specific to borderline personality disorder. Harv Rev Psychiatry. 1998 Nov-Dec;6(4):201-7.

74 Lieb K, Zanarini MC, Schmahl C, Linehan MM, Bohus M. Borderline personality disorder. Lancet. 2004 Jul;364(9432):453-61.

75 Meerwijk EL, Shattell MM. We need to talk about psychological pain. Issues Ment Health Nurs. 2012 Apr;33(4):263-5.

76 Chapman AL, Gratz KL, Brown MZ. Solving the puzzle of deliberate self-harm: the experiential avoidance model. Behav Res Ther. 2006 Mar;44(3):371-94. 
77 Monson CM, Price JL, Rodriguez BF, Ripley MP, Warner RA. Emotional deficits in military-related PTSD: an investigation of content and process disturbances. J Trauma Stress. 2004 Jun;17(3):275-9.

78 Hezel DM, Riemann BC, McNally RJ. Emotional distress and pain tolerance in obsessive-compulsive disorder. J Behav Ther Exp Psychiatry. 2012 Dec;43(4):981-7.

79 Baker C. Subjective experience of symptoms in schizophrenia. Can J Nurs Res. 1996;28(2): 19-35.

80 Elman I, Zubieta JK, Borsook D. The missing $\mathrm{p}$ in psychiatric training: why it is important to teach pain to psychiatrists. Arch Gen Psychiatry. 2011 Jan;68(1):12-20.

81 Engel GL. Psychogenic pain and pain-prone patient. Am J Med. 1959 Jun;26(6):899-918.

82 Blumer D, Heilbronn M. Chronic pain as a variant of depressive disease: the pain-prone disorder. J Nerv Ment Dis. 1982 Jul;170(7): 381-406.

83 Wachholtz A, Fitch CE. Role of religion and spirituality in the patient pain experience. In: Deer T, Pope J, Lamer T, Provenzano D, editors. Deers's treatment of pain. Cham: Springer; 2019. pp. 117-23.

84 da Spinetoli O. L'inutile fardello (The useless burden). Milan: Chiarelettere; 2017.
85 van Heeringen K, Van den Abbeele D, Vervaet $\mathrm{M}$, Soenen $\mathrm{L}$, Audenaert K. The functional neuroanatomy of mental pain in depression. Psychiatry Res. 2010 Feb;181(2):141-4.

86 Balon R, Chouinard G, Cosci F, Dubovsky SL, Fava GA, Freire RC, et al. International Task Force on Benzodiazepines. Psychother Psychosom. 2018;87(4):193-4.

87 Benasi G, Guidi J, Offidani E, Balon R, Rickels $\mathrm{K}$, Fava GA. Benzodiazepines as a monotherapy in depressive disorders: a systematic review. Psychother Psychosom. 2018;87(2):6574.

88 Chouinard G, Samaha AN, Chouinard VA, Peretti CS, Kanahara N, Takase M, et al. Antipsychotic-induced dopamine supersensitivity psychosis: pharmacology, criteria and therapy. Psychother Psychosom. 2017;86(4): 189-219.

89 Fava GA, Guidi J, Rafanelli C, Rickels K. The clinical inadequacy of the placebo model and the development of an alternative conceptual framework. Psychother Psychosom. 2017; 86(6):332-40.
90 Finan PH, Garland EL. The role of positive affect in pain and its treatment. Clin J Pain. 2015 Feb;31(2):177-87.

91 Nierenberg B, Mayersohn G, Serpa S, Holovatyk A, Smith E, Cooper S. Application of well-being therapy to people with disability and chronic illness. Rehabil Psychol. 2016 Feb;61(1):32-43.

92 Wright JH, McCray LW. Breaking free from depression. Pathways to wellness. New York: Guilford; 2012.

93 Blendon RJ, Benson JM. The Public and the Opioid-Abuse Epidemic. N Engl J Med. 2018 Feb;378(5):407-11.

94 Finan PH, Remeniuk B, Dunn KE. The risk for problematic opioid use in chronic pain: what can we learn from studies of pain and reward? Prog Neuropsychopharmacol Biol Psychiatry. 2018 Dec;87 Pt B:255-62.

95 Garland EL, Howard MO, Zubieta JK, Froeliger B. Restructuring hedonic dysregulation in chronic pain and prescription opioid misuse: Effects of Mindfulness-Oriented Recovery Enhancement on Responsiveness to Drug Cues and Natural Rewards: effects of mindfulness-oriented recovery enhancement on responsiveness to drug cues and natural rewards. Psychother Psychosom. 2017;86(2): $111-2$. 